\title{
Rheological properties and microbiological characteristics of kefir produced from different milk types
}

\author{
Derya SAYGILI ${ }^{1 *}$ (D), Deniz DÖNER ${ }^{2}$, Filiz IÇĊER ${ }^{3}$, Cem KARAGÖZLÜ $^{4}$
}

\begin{abstract}
Kefir is a refreshing fermented dairy product which has flowing consistency, uniform and bright appearance with mild yeast taste and flavor. Traditional or industrial methods can be applied for the production of kefir using kefir grains or lyophilized culture. Changes in product rheology caused by the using different types of milk and different incubation temperatures in kefir production are effective on selecting the equipment such as pump, pipeline, mixer, filling machine. In this study, microbiological flora and rheological properties of kefir were investigated for cow, sheep or goat milks with kefir grain or lyophilized culture. The pasteurized cow, sheep and goat milk were cooled to $28^{\circ} \mathrm{C}$ and fermented with kefir grain and incubated at $20^{\circ} \mathrm{C}, 25^{\circ} \mathrm{C}$ or $30^{\circ} \mathrm{C}$ for 24 hours. Then, the grains were filtered and stored at $+4^{\circ} \mathrm{C}$ for 24 hours. At the end of the storage period, rheological and microbiological analyzes were carried out on kefir samples. The same procedures and analyzes were carried out lyophilized culture. It was found that the incubation application at different temperatures was effective on the consistency coefficient even in the fluid type unchangeable samples.
\end{abstract}

Keywords: kefir; incubation; quality; rheology.

Practical Application: The use of different milk types changes kefir characteristics and results can be used for developing alternative fermented beverages.

\section{Introduction}

Kefir whose origin is the Caucasian Mountains is an important fermented milk beverage. Bright appearance, unique color and uniform flowing consistency occur as a result of activities of specific microorganism. The word 'kefir' is derived from the word 'keyf' which means nice in Turkish. It is known with many different names such as; kephir, kiaphur, kefer, knapon, kepi, kefir and kippi in Argentina, Taiwan, Portugal, Turkey and France (Thompson et al., 1990; Chin-Wen et al., 1999; Gülmez \& Güven, 2003; Santos et al., 2003; Açik et al., 2020). The kefir grain has a diverse spectrum of species including especially lactic acid bacteria (Lactococci, Lactobacilli, Leuconostoc). It also has a spectrum of certain yeasts (Saccharomyces, Kluyveromyces and Candida) and acetic acid bacteria (Acetobacter). This microflora is located within the polysaccharide matrix called kefiran (Paraskevopoulou et al., 2003; Kesenkas et al., 2013). Nutritional properties of kefir increase with partial protein and lactose disintegration as well as synthesis of some vitamins during kefir fermentation. It has been reported that kefir is a dairy product rich in calcium, phosphorus, amino acids, folic acid and B vitamins (Farnworth, 2005). It has been reported that the lactic acid, acetic acid, $\mathrm{CO}_{2}$ and various aromatic components provide refreshing taste and mildly sweet flavor which is specific to kefir (Ötleş \& Çağındı, 2003). Recent studies were investigate the potential of kefir from different milk types, grain cultures and its use as alternative functional food (Silva et al., 2018a, b;
Demirci et al., 2019; Kivanc \& Yapici, 2019; Tomar et al., 2020; Mitra \& Ghosh, 2020; Karaçalı et al., 2018; Dong et al., 2018). While it is preferred to use lyophilized culture in commercial kefir production, kefir grain production method can also be used. Kefir grains contain a wide microflora (Bensmira et al., 2010). The rheological properties are particularly important to determine different interactions in new kefir formulation. The information on the rheological characteristics of kefir is very important from the storage and carrying (Doğan, 2011). Dimitreli \& Antoniou (2011) have reported that incubation temperature have the highest effect on the rheological properties of kefir. Also, the addition of caseinates have important effect on rheological properties of kefir. In a study on the rheological properties of kefir with different fat contents, the change in the rheological behavior was examined. The effect of the production method of kefir and the composition of the milks were emphasized when the flow behavior was determined (Ar1 et al., 2012).

Studies show that the effect of rheological properties on kefir quality is largely important, but the number of studies is limited. There is no research on the effects of production conditions on the quality of kefir. The aim of this study was to make a contribution to the literature on the effect of different incubation temperatures on the quality of kefir. There is no information available on the rheology of kefir prepared with different milk types (cow, sheep, goat), therefore the present study 
aimed to determine the rheological behavior and microbiological properties of kefir produced with different milks.

\section{Materials and methods}

\subsection{Material}

Three different milk types (cow, sheep and goat) used in the study were obtained from the Department of Animal Science in the Faculty of Agriculture in Ege University. CHOZITTM Kefir DC LYO 10001 (Danisco, Germany) was used as a lyophilized starter culture for the production of kefir. The culture contains Leuconostoc mesenteroides spp. cremoris, Lactococcus lactis spp. lactis, Lactococcus lactis spp. cremoris, Lactococcus lactis spp. diacetylactis, Lactobacillus kefyr, Kliyveromyces marxianus and Saccharomyces unisporus. Kefir grains were obtained from the kefir grain collection of the Department of Dairy Technology, Faculty of Agriculture, Ege University.

\subsection{Method}

Determination of $\mathrm{pH}$

$\mathrm{pH}$ values were measured with HANNA pH211 Microprocessor pHmeter (Portugal).

\section{Rheological measurements}

Rheological properties were determined with a Brookfield brand (LVDV-II Brookfield Engineering Laboratories, USA) viscometer. Calculations were made taking the measurements that give torque values in the range of 0 to $200 \mathrm{rpm}$ into account, which range from 10 to $90 \%$. The models and equations are given in Table 1. Accordingly, $\mu$ is the Newtonian fluid viscosity (Pa.s), $\tau$ is the shear stress $(\mathrm{Pa}), \tau 0$ is the initial shear stress $(\mathrm{Pa}), \mathrm{n}$ is the fluid behavior index, $\kappa$ is the coefficient of consistency (Pa.sn), $\sigma$ is the shear rate $(1 / \mathrm{s})$. The apparent viscosity values, consistency

Table 1. Mathematical models.

\begin{tabular}{cccc}
\hline Model & \multicolumn{2}{c}{ Equation } & Reference \\
\hline 1 & Newton & $\tau=\mu \times \dot{\gamma}$ & İçier et al. (2015) \\
2 & Bingham & $\tau-\tau_{0}=K \times \dot{\gamma}$ & İçier et al. (2015) \\
3 & Power -Law & $\tau=K \times \gamma^{n}$ & İçier et al. (2015) \\
4 & Herschel-Bulkley & $\tau-\tau_{0}=K \times \gamma^{n}$ & İçier et al. (2015) \\
\hline
\end{tabular}

coefficient, initial shear stress and flow behavior index values of kefir samples produced from different milks were determined.

Apparent viscosity values $\left(\mu_{\text {apparent }}\right)$ are used for non-Newtonian fluids. In the study, the apparent viscosity values were calculated depending on the $\mathrm{K}$ and $\mathrm{n}$ values for $100 \mathrm{rpm}$ (Equation 1).

$$
\mu_{\text {apparent }}=K^{*} \gamma^{n-1}
$$

Samples were stored at refrigerator temperature $\left(<4{ }^{\circ} \mathrm{C}\right)$ after kefir production. The analyses were conducted with three parallels. In rheological analyses, preliminary experiments were carried out, spindle 18 and spindle 34 were used.

\section{Microbiological analysis}

Ringer solution (Merck) at a concentration of $1 \mathrm{~g} / \mathrm{L}$ was used to prepare the dilutions. Lactobacilli counts were performed using MRS medium ( $\mathrm{pH} 6.5 \pm 0.2$ ) (Merck). Lactobacilli plates were incubated at $30{ }^{\circ} \mathrm{C}$ under anaerobic conditions $\left(5 \% \mathrm{CO}_{2}\right.$ ) for three days (De Man et al., 1960). Lactococci counts were carried out on M17 medium $(\mathrm{pH} 7.2 \pm 0.2)$ (Merck) at an incubation temperature of $30^{\circ} \mathrm{C}$ under anaerobic conditions for two days (Terzaghi \& Sandine, 1975). Yeasts were inoculated into YGC medium ( $\mathrm{pH} 7.0 \pm 0.2)$ (Merck) at $25^{\circ} \mathrm{C}$ for five days (International Organization for Standardization, 1992). The calculations were conducted by counting the columns between 10-300 collony in Petrillas in two consecutive dilutions. Results were calculated as $\log \mathrm{cfu} / \mathrm{mL}$.

\section{Kefir production}

Kefir productions were carried out in Pilot Dairy Processing Facility, Dairy Technology, Faculty of Agriculture, Ege University. Kefir production according to the raw material, culture and incubation temperatures was schematized in Figure 1.

Kefir produced using kefir grains or lyophilized culture from cow, sheep and goat milk was incubated at $20^{\circ} \mathrm{C}, 25^{\circ} \mathrm{C}$ or $30^{\circ} \mathrm{C}$. The flowchart for kefir production is as shown in Figure 2. Kefir samples were taken out of the incubator and analyzed after storage for 24 hours.

\subsection{Statistical analyses}

Statistical Package for Social Science (SPSS) package program (version 15.0) was used for the evaluation of experimental data. The significance of the differences between rheological properties and kefir microbiology in terms of different incubation

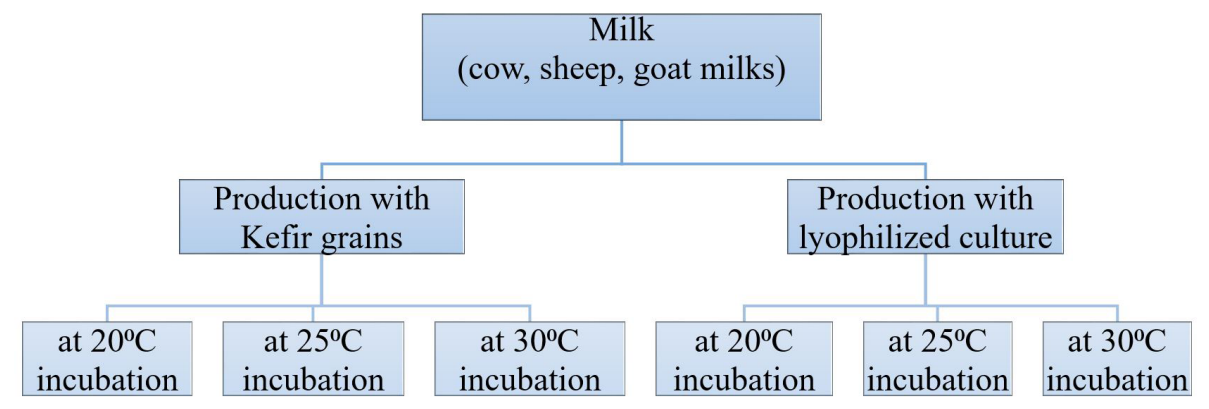

Figure 1. Sample distribution of kefir production. 


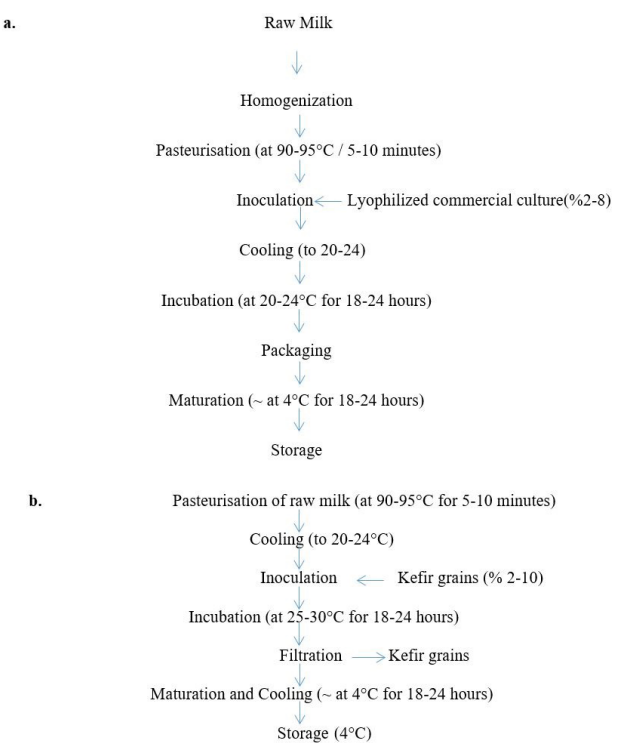

Figure 2. Production of kefir (a) with lyophilized culture; (b) with kefir grains.

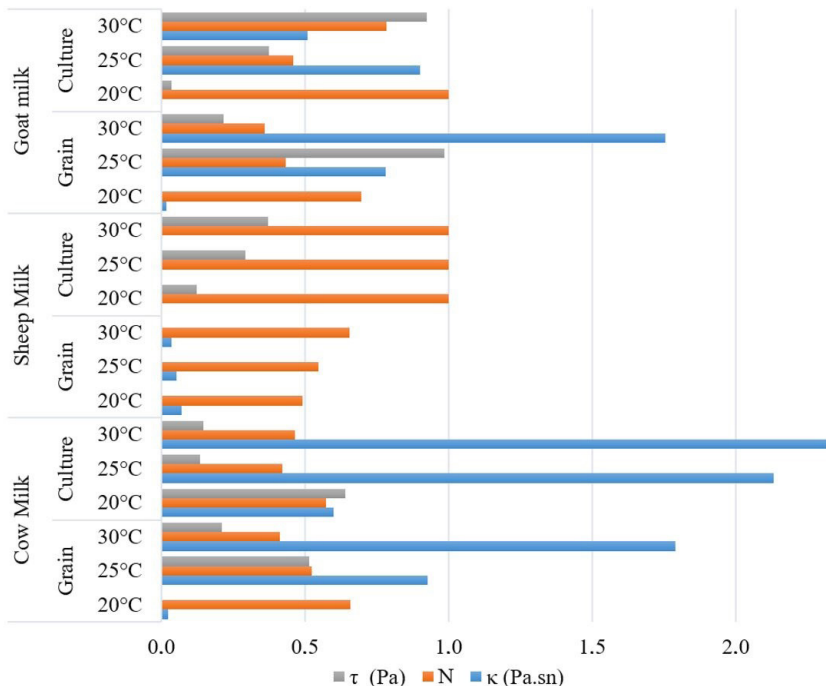

Figure 3. Rheological characteristics of different kefir types.

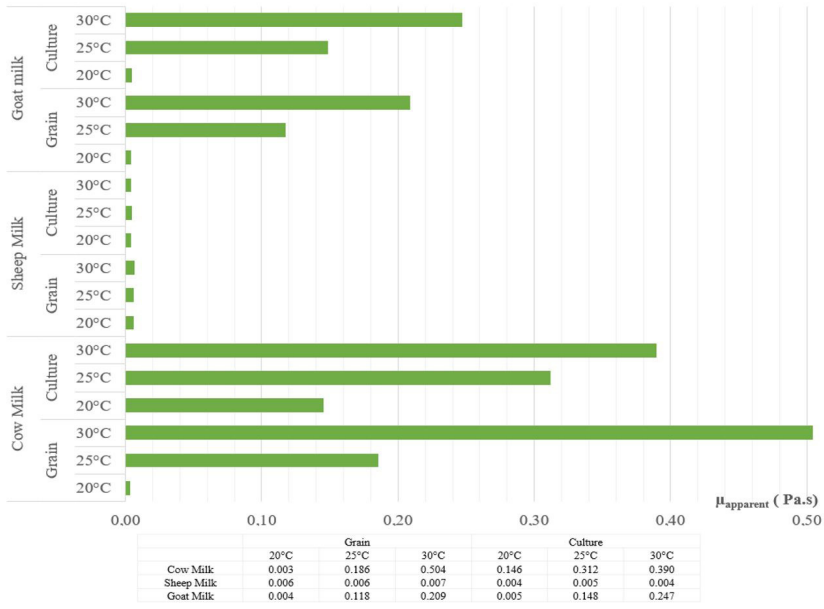

Figure 4. Apparent viscosity of different kefir types. temperatures in the mean values $(\mathrm{p}<0.05)$ were determined by the Duncan multiple comparison test in the SPSS. The kefir production and analyzes was applied 2 different times.

\section{Results and discussion}

\subsection{Rheological properties and $\mathrm{pH}$ values}

Both the fermentation process and incubation temperature were important criteria to obtained the desired consistency in kefir. The rheological properties of kefir samples which were incubated at different temperatures are given at Figure 3 and 4 . The $\mathrm{pH}$ values of the kefir samples produced from different milks ranged from 4.37 to 4.80 after fermentation (Figure 5). The findings were similar to those reported by Satir \& GuzelSeydim (2016). Similar to the results reported in previous studies, rheological behavior of kefir was determined as Newtonian fluid model (Ertekin \& Güzel-Seydim, 2010; Sady et al., 2009; Doğan, 2011). In particular, sheep and goat milk had lower apparent viscosities than that of cow milk, and a temperature increase of $5{ }^{\circ} \mathrm{C}$ appeared to characterize the fluidity of kefir. This data was verifying the similar results obtained by Tratnik et al. (2006) which evaluated the quality of kefir obtained from cow and goat milk. In the mentioned study, goat and cow milk were fortified with $\% 2$ skimmed milk powder, whey protein concentrate or inulin. Samples were incubated at $25^{\circ} \mathrm{C}$ and stored at $5{ }^{\circ} \mathrm{C}$. Tratnik announced that goats samples have significantly lower viscosity.

In our study, the change in the consistency coefficient was reported to significant for cow milk samples. The rheological behavior of kefir samples incubated at $20^{\circ} \mathrm{C}, 25^{\circ} \mathrm{C}$ or $30^{\circ} \mathrm{C}$ was depending on the incubation temperature and the milk type (cow, sheep and goat milk) (Figure 3).

Kefir samples produced with cow milk at $20{ }^{\circ} \mathrm{C}$ were consistent with the Exponential model, while kefir samples with the increase in temperature were consistent with the HerschelBulkley model. As the incubation temperature increased, the consistency coefficient of the kefir increased $(p<0.05)$, however there was no change in flow type. This change in the consistency

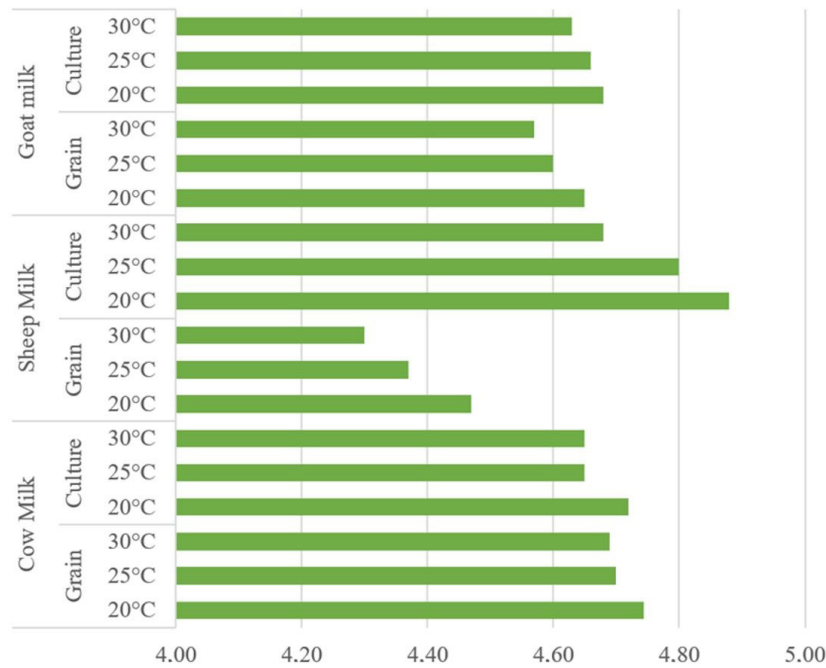

Figure 5. $\mathrm{pH}$ values of kefir samples. 
of kefir produced from cow milk, appears to be parallel with the decrease in $\mathrm{pH}$ value. Kefir samples produced from sheep milk with kefir grains showed rheological behaviors consistent with the Exponential model. When the consistency coefficients of the samples were evaluated according to the incubation temperature, the difference between the consistency coefficients of the sheep milk kefir produced with the kefir grain was statistically significant $(p<0.05)$. There was an increase in the consistency coefficient of kefir samples produced from cow milk using kefir grains, similar to the increase in incubation temperature. The consistency coefficient of the kefir produced from sheep milk using kefir grains had a tendency to decrease with the increase in temperature.

It was reported that there was no statistical difference between the consistency coefficients and the Bingham model was determined as the best fitting model for each production conducted using lyophilized culture in the same group for three different temperature settings ( $\mathrm{p}>0.05)$.

Evaluating the kefir production from goat milk, it was observed that a temperature increase of $5^{\circ} \mathrm{C}$ in the kefir produced using the kefir grain changed the rheological behavior of the kefir. In this study, goat milk reported as the only milk type to be fit with three different models. In the production using kefir grains, consistency with the Exponential model was determined in samples incubated at $20^{\circ} \mathrm{C}$ and the Hershel-Bulkley model was determined as the best fitting model for samples incubated at $25^{\circ} \mathrm{C}$ and $30^{\circ} \mathrm{C}$. Hershel-Bulkley model results are determinate for kefir samples produced by using culture. The change in the consistency coefficient observed with the increase in incubation temperature in cow and sheep milk was also found in kefir produced with goat milk. Kefir samples that fit the Herschel-Bulkley model had about twice as high as the consistency coefficients when the temperature increase of about $5{ }^{\circ} \mathrm{C}$.

Apparent viscosity values were calculated by considering the rheological data of kefir samples produced from different types of milk. Examining the apparent viscosity values for cow milk, it was determined that the viscosity values also increased with the increase in incubation temperature. This increase in viscosity values was statistically significant $(\mathrm{p}<0.05)$. The highest viscosity values in kefir produced from sheep milk for with kefir grains (at $30^{\circ} \mathrm{C}$ incubation temperature) were determined to be 0.0067 Pa.s. The apparent viscosity in kefir incubated at $25^{\circ} \mathrm{C}$ in lyophilized culture was determined to be 0.0050 Pa.s. The difference between the apparent viscosity values of kefir incubation at different temperatures from sheep milk was found to be statistically not significant and the viscosity values of all temperatures are shown in Figure 4. For kefir samples produced from goat milk showed similar behavior to that produced from cow milk. Higher viscosity values were obtained for both milk types as the incubation temperature increased. Regarding goat milk kefir, the temperature increase from $25^{\circ} \mathrm{C}$ to $30^{\circ} \mathrm{C}$ for both grains and culture-grown specimens appears to provide an increase in viscosity by about doubled. While this change in viscosity values is statistically significant $(\mathrm{p}<0.05)$, similar to that reported by Vianna et al. (2017), it indicates the importance of incubation temperature preferred in kefir production.

\subsection{Microbiological properties}

Kefir was produced from cow, sheep and goat milk at three different incubation temperatures using kefir grains and or starter culture. Microbiological analyzes were carried out in kefir samples stored for about 1 day after production. The microbiological results of kefir samples are shown in Figure 6.

Each kefir sample (cow milk, sheep milk, goat milk) produced from different milk was analyzed within itself statistically. In kefir produced from grains and culture from cow milk, the LAB
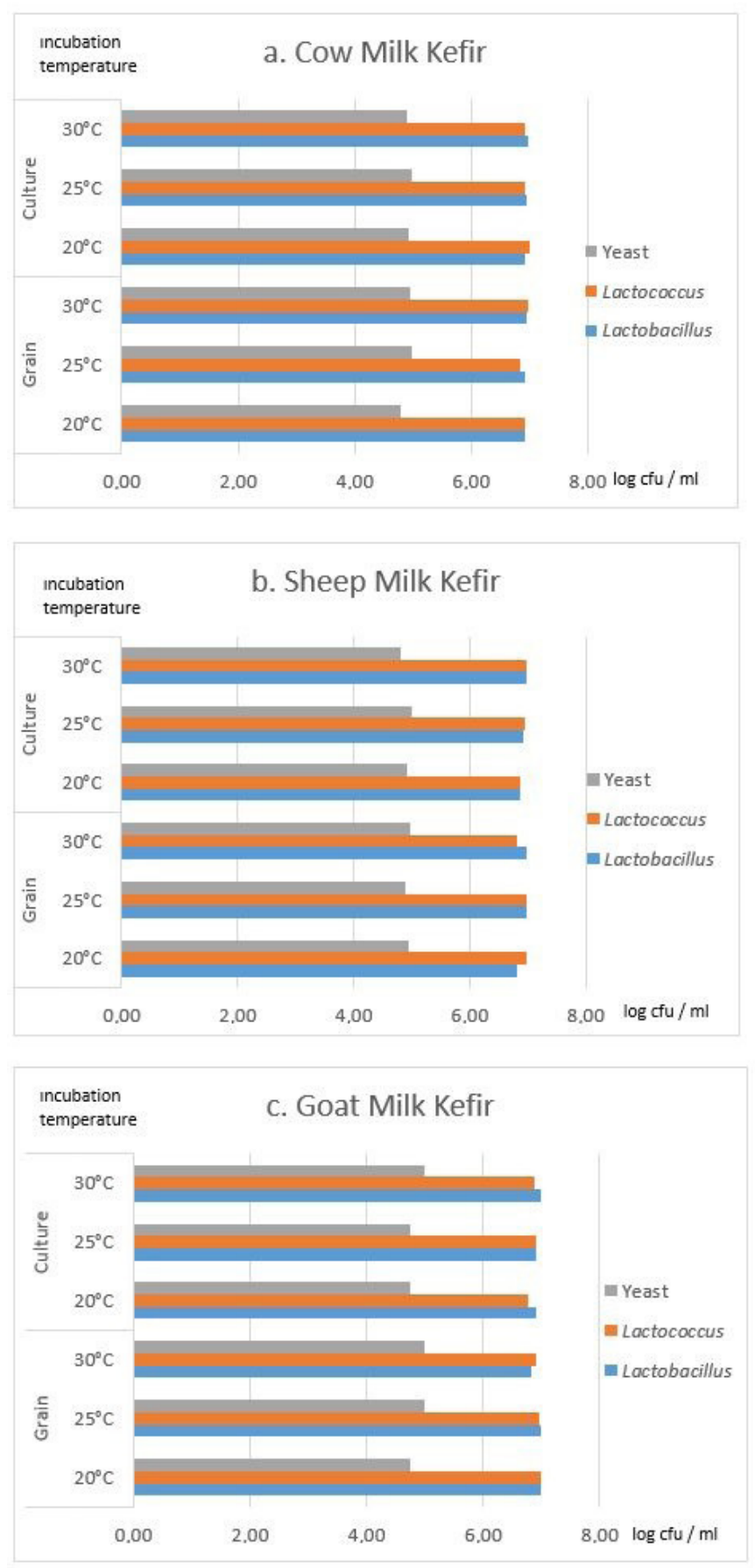

Figure 6. Microbiological results of kefir samples. (a) Cow milk kefir; (b) Sheep milk kefir; (c) Goat milk kefir. 
was estimated min. $6.84 \mathrm{cfu} / \mathrm{mL}$ and $\max .7 .00 \mathrm{cfu} / \mathrm{mL}$. There were no statistical differences between the samples in terms of different production methods and incubation temperatures $(p>0.05)$. Lactococci levels were similar to those reported by Kilic et al. (1999).

It can be said that the microbiological quality for each incubation temperature were the same in cow milk which produced grain and culture. Yeast counts in kefir samples produced from cow milk varied between $4.78 \log \mathrm{cfu} / \mathrm{mL}$ and $4.98 \log \mathrm{cfu} /$ $\mathrm{mL}$. The difference between these values was statistically not significant $(p>0.05)$. The yeast counts were similar to those reported Kilic et al. (1999).

The results of microbiological analysis of kefir samples produced with sheep and goat milk were in agreement with the results reported by Chen et al. (2005). Statistical calculations for cow milk kefir were also evaluated for sheep and goat milk. Similar results were obtained with cow milk. Different incubation temperatures had no significant effect on the microbiological properties of the samples $(\mathrm{p}>0.05)$. These results were similar to those reported by Kök-Taş et al. (2013). In this study it was planned to analyze rheological properties of kefirs with different milk types. Further studies should investigate the sensory methods due to lack information about related rheological properties' effect on consumer preferences (Judacewski et al., 2019; Silva et al., 2018a, b; Costa et al., 2020; Vieira et al., 2020).

\section{Conclusion}

As a result, kefir samples produced from cow milk by grain and culture were found to fit the Hershel-Bulkley model even at different incubation temperatures, whereas only kefir incubated at $20^{\circ} \mathrm{C}$ fitted the Exponential model. While the kefir produced using the kefir grains from sheep milk was consistent with the Exponential model, it was determined that the kefir produced using the culture fitted the Bingham model. It was observed that the consistency coefficients obtained from the sheep milk tended to decrease with the increase in incubation temperature as opposed to the data obtained from the cow milk. In the study, it was reported that kefir produced from goat milk fitted all three models. The samples produced using kefir grains at $20^{\circ} \mathrm{C}$ fitted the Exponential model whereas kefir samples produced using culture at $20{ }^{\circ} \mathrm{C}$ fitted the Bingham model fluid type. Other incubation temperature applications shown Herschel-Bulkley model adaptation regardless of the grain and culture use. It was observed that different incubation temperatures are much more effective in sheep and goat milk than in cow milk to determine the fluid type $(\mathrm{p}<0.05)$. In this study, it was determined how important the incubation temperatures are in determining the fluid type of kefir, as well as the grain and lyophilized culture use. When the microbiological analyzes were examined, it was concluded that the effect of the production method and incubation temperature on microbiological quality in kefir samples was not significant in the $95 \%$ confidence interval $(\mathrm{p}>0.05)$. It was emphasized that the change in the rheological properties, in which the differences were at a significant level but did not affect the microbiological quality statistically. It is thought that this study will shed a light for the production at industrial level who are looking for new products.

\section{References}

Açik, M., Çakiroğlu, F. P., Altan, M., \& Baybo, T. (2020). Alternative source of probiotics for lactose intolerance and vegan individuals: sugary kefir. Food Science and Technology, 40(3), 523-531. http:// dx.doi.org/10.1590/fst.27919.

Arı, P., Eroğlu, S., İçier, F., Karagözlü, C., \& Obuz, E. (2012). Farklı yağ içeriklerine sahip kefirlerin inkübasyon süresince reolojik özellikleri ve ph değerlerindeki değişimin incelenmesi. In III Geleneksel Gıdalar Sempozyumu. Konya.

Bensmira, M., Nsabimana, C., \& Jiang, B. (2010). Effects of fermentation conditions and homogenization pressure on the rheological properties of Kefir. Food Science and Technology, 43, 1180-1184.

Chen, M. J., Liu, J. R., Lin, C. W., \& Yeh, Y. T. (2005). Study of the microbial and chemical properties of goat milk kefir produced by inoculation with Taiwanese kefir grains. Asian-Australasian Journal of Animal Sciences, 18(5), 711-715. http://dx.doi.org/10.5713/ajas.2005.711.

Chin-Wen, L., Hsiao-Ling, C., \& Liu, J. R. (1999). Identification and characterisation of lactic acid bacteria and yeasts isolated from kefir grains in Taiwan. Australian Journal of Dairy Technology, 54(1), 14.

Costa, G. M., Paula, M. M., Costa, G. N., Esmerino, E. A., Silva, R., Freitas, M. Q., Barão, C. E., Cruz, A. G., \& Pimentel, T. (2020). Preferred attribute elicitation methodology compared to conventional descriptive analysis: a study using probiotic yogurt sweetened with xylitol and added with prebiotic components. Journal of Sensory Studies, 35(6), e12602. http://dx.doi.org/10.1111/joss.12602.

De Man, J. D., Rogosa, M., \& Sharpe, M. E. (1960). A medium for the cultivation of Lactobacilli. The Journal of Applied Bacteriology, 23(1), 130-135. http://dx.doi.org/10.1111/j.1365-2672.1960.tb00188.x.

Demirci, A. S., Palabiyik, I., Ozalp, S., \& Tirpanci Sivri, G. (2019). Effect of using kefir in the formulation of traditional Tarhana. Food Science and Technology, 39(2), 358-364. http://dx.doi.org/10.1590/fst.29817.

Dimitreli, G., \& Antoniou, K. D. (2011). Effect of incubation temperature and caseinates on the rheological behaviour of Kefir. Procedia Food Science, 1, 583-588. http://dx.doi.org/10.1016/j.profoo.2011.09.088.

Doğan, M. (2010). Rheological behaviour and physicochemical properties of kefir with honey. Journal für Verbraucherschutz und Lebensmittelsicherheit, 6(3), 327-332. http://dx.doi.org/10.1007/ s00003-010-0643-6.

Dong, J., Liu, B., Jiang, T., Liu, Y., \& Chen, L. (2018). The biofilm hypothesis: the formation mechanism of Tibetan kefir grains. International Journal of Dairy Technology, 71, 44-50. http://dx.doi. org/10.1111/1471-0307.12473.

Ertekin, B., \& Güzel-Seydim, Z. B. (2010). Effect of fat replacers on kefir quality. Journal of the Science of Food and Agriculture, 90(4), 543-548. http://dx.doi.org/10.1002/jsfa.3855. PMid:20355079.

Farnworth, E.R. (2005). Kefir: a complex probiotic. Food Science and Technology Bulletin: Functional Foods, 2(1), 1-17.

Gülmez, M., \& Güven, A. (2003). Survival of Escherichia coli O157:H7, Listeria monocytogenes $4 \mathrm{~b}$ ve Yersinia enterocolitica $\mathrm{O} 3$ in different yoghurt ve kefir combinations as prefermentation contaminant. Journal of Applied Microbiology, 95(3), 631-636. http://dx.doi. org/10.1046/j.1365-2672.2003.02016.x. PMid:12911712.

İçier, F., Gündüz, G. T., Yılmaz, B., \& Memeli, Z. (2015). Changes on some quality characteristics of fermented soy milk beverage with added apple juice. Lebensmittel-Wissenschaft + Technologie, 63(1), 57-64. http://dx.doi.org/10.1016/j.lwt.2015.03.102.

International Organization for Standardization - ISO. (1992). ISO/ DIS 6611: milk and milk products: enumeration of yeast and moulds: colony count technique at $25^{\circ} \mathrm{C}$. Geneva. 
Judacewski, P., Los, P. R., Lima, L. S., Alberti, A., Zielinski, A. A. F., \& Nogueira, A. (2019). Perceptions of Brazilian consumers regarding white mould surface-ripened cheese using free word association. International Journal of Dairy Technology, 72(4), 585-590. http:// dx.doi.org/10.1111/1471-0307.12649.

Karaçalı, R., Özdemİr, N. İ., \& Çon, A. H. (2018). Aromatic and functional aspects of kefir produced using soya milk and Bifidobacterium species. International Journal of Dairy Technology, 71(4), 921-933. http://dx.doi.org/10.1111/1471-0307.12537.

Kesenkas, H., Yerlikaya, O., \& Ozer, E. (2013). A functional milk beverage: Kefir. Agro Food Industry Hi-Tech, 24, 53-55.

Kilic, S., Uysal, H., Akbulut, N., Kavas, G., \& Kesenkaş, H. (1999). Chemical, microbiological and sensory changes in ripening kefirs produced from starters and grains. Ziraat Fakultesi Dergisi Cilt, 36(1), 111-118.

Kivanc, M., \& Yapici, E. (2019). Survival of Escherichia coli O157: H7 and Staphylococcus aureus during the fermentation and storage of kefir. Food Science and Technology, 39(Suppl. 1), 225-230. http:// dx.doi.org/10.1590/fst.39517.

Kök-Taş, T., Seydim, A. C., Ozer, B., \& Guzel-Seydim, Z. B. (2013). Effects of different fermentation parameters on quality characteristics of kefir. Journal of Dairy Science, 96(2), 780-789. http://dx.doi. org/10.3168/jds.2012-5753. PMid:23245957.

Mitra, S., \& Ghosh, B. C. (2020). Quality characteristics of kefir as a carrier for probiotic Lactobacillus rhamnosus GG. International Journal of Dairy Technology, 73(2), 384-391. http://dx.doi.org/10.1111/1471-0307.12664.

Ötleş, S., \& Çağındı, O. (2003). Kefir: a probiotic dairy-composition, nutritional and therapeutic aspects. Pakistan Journal of Nutrition, 2(2), 54-59. http://dx.doi.org/10.3923/pjn.2003.54.59.

Paraskevopoulou, A., Athanasiadis, I., Kanellaki, M., Bekatorou, A., Blekas, G., \& Kiosseoglou, V. (2003). Functional properties of single cell protein produced by kefir microflora. Food Research International, 36(5), 431-438. http://dx.doi.org/10.1016/S0963-9969(02)00176-X.

Sady, M., Domagała, J., Najgebauer-Lejko, D., \& Grega, T. (2009). Effect of whey protein concentrate addition on texture and rheological properties of kefir produced from skimmed milk. Biotechnology in Animal Husbandry, 25(5-6), 763-771.

Santos, A., San Mauro, M., Sanchez, A., Torres, J. M., \& Marquina, D. (2003). The antimicrobial properties of different strains of Lactobacillus spp. isolated from kefir. Systematic and Applied Microbiology, 26(3), 434-437. http://dx.doi.org/10.1078/072320203322497464. PMid:14529186.
Satir, G., \& Guzel-Seydim, Z. B. (2016). How kefir fermentation can affect product composition? Small Ruminant Research, 134, 1-7. http://dx.doi.org/10.1016/j.smallrumres.2015.10.022.

Silva, C. F. G. D., Santos, F. L., Santana, L. R. R. D., Silva, M. V. L., \& Conceição, T. D. A. (2018a). Development and characterization of a soymilk Kefir-based functional beverage. Food Science and Technology, 38(3), 543-550. http://dx.doi.org/10.1590/1678-457x.10617.

Silva, H. L. A., Balthazar, C. F., Silva, R., Vieira, A. H., Costa, R. G. B., Esmerino, E. A., \& Cruz, A. G. (2018b). Sodium reduction and flavor enhancer addition in probiotic prato cheese: contributions of quantitative descriptive analysis and temporal dominance of sensations for sensory profiling. Journal of Dairy Science, 101(10), 8837-8846. http://dx.doi.org/10.3168/jds.2018-14819. PMid:30077456.

Terzaghi, B. E. S., \& Sandine, W. E. (1975). Improved medium for lactic streptococci and their bacteriophages. Applied Microbiology, 29(6), 807-813. http://dx.doi.org/10.1128/AM.29.6.807-813.1975. PMid:16350018.

Thompson, J. K., Johnston, D. E., Murphy, R. J., \& Collins, M. A. (1990). Characteristics of a milk fermentation from rural Northern Ireland which resembles kefir. International Journal of Food Science \& Technology, 14(1), 35-49.

Tomar, O., Akarca, G., Çağlar, A., Beykaya, M., \& Gök, V. (2020). The effects of kefir grain and starter culture on kefir produced from cow and buffalo milk during storage periods. Food Science and Technology, 40(1), 238-244. http://dx.doi.org/10.1590/fst.39418.

Tratnik, L., Bozanic, R., Herceg, Z., \& Drgalic, I. (2006). The quality of plain and supplemented kefir from goat's and cow's milk. International Journal of Dairy Technology, 59(1), 40-46. http://dx.doi. org/10.1111/j.1471-0307.2006.00236.x.

Vianna, F. S., Canto, A. C. V. C. S., Costa-Lima, B. R. C., Salim, A. P. A. A., Costa, M. P., Balthazar, C. F., Oliveira, B. R., Rachid, R. P., Franco, R. M., Conte-Junior, C. A., \& Silva, A. C. O. (2017). Development of new probiotic yoghurt with a mixture of cow and sheep milk: effects on physicochemical, textural and sensory analysis. Small Ruminant Research, 149, 154-162. http://dx.doi.org/10.1016/j. smallrumres.2017.02.013.

Vieira, A. H., Balthazar, C. F., Rocha, R. S., Silva, R., Guimaraes, J. T., Pagani, M. M., Pimentel, T. C., Esmerino, E. A., Silva, M. C., Tonon, R. V., Cabral, L. M., Freitas, M. Q., \& Cruz, A. G. (2020). The free listing task for describing the sensory profiling of dairy foods: a case study with microfiltered goat whey orange juice beverage. Journal of Sensory Studies, 35(5), e12594. http://dx.doi. org/10.1111/joss.12594. 